\title{
Rancang Bangun Aplikasi Absensi Mahasiswa Pada Platform Android
}

\author{
Endah Puspitarini $^{1}$, Roudhotul Hanifa ${ }^{2}$ Faridatun Nadziroh $^{3}$ \\ Program Studi/Jurusan Otomasi Perkantoran Akademi Komunitas Semen Indonesia Gresik \\ Email: ${ }^{1}$ endahpuspitarini87@gmail.com,_2 roudhotulhanifa242@gmail.com, ${ }^{3}$ faridatun.nadziroh@gmail.com
}

\begin{abstract}
Abstrak: Penggunaan perangkat mobile mewabah kian cepat dalam kehidupan sehari-hari manusia. Didukung dengan adanya pengembangan aplikasi mobile yang begitu inovatif dan variatif, merupakan salah satu penyebabnya. Pengembangan aplikasi mobile bertujuan untuk mendukung hampir segala kegiatan manusia, seperti media sosial, dan juga khususnya mendukung untuk kegiatan belajar mengajar. Proses absensi merupakan suatu proses yang mendukung kegiatan belajar mengajar, dimana data absensi digunakan pada perkuliahan sebagai salah satu acuan dalam pengambilan keputusan penilaian terhadap mahasiswa. Data absensi tergolong data yang cukup riskan untuk terjadi kerusakan, dikarenakan bentuknya yang masih berupa lembaran kertas. Guna meminimalisir kerusakan laporan absensi tersebut, maka dirancanglah sebuah aplikasi berbasis android yang dapat menanagani proses absensi. Aplikasi yang dibangun, selain menangani proses absensi dalam perkuliahan, juga memiliki modul tambahan yaitu rekap absensi dimana data absensi yang tersimpan, selanjutnya direkapitulasi dan ditampilkan dalam sebuah laporan digital yang bisa diakses dimana saja dan kapan saja. Rancang bangun aplikasi juga memiliki tingkat pertumbuhan alokasi data yang relative kecil yaitu kurang lebih 11.7MB dengan asumsi perkuliahan di Akademi Komunitas Semen Indonesia dalam satu semester.
\end{abstract}

Kata Kunci: Absensi, Perangkat Mobile, Android Mobile

\begin{abstract}
The use of mobile devices is becoming increasingly fast in the daily lives of humans. Supported by the development of mobile applications that are so innovative and varied, is one of the causes. The development of mobile applications aims to support almost all human activities, such as social media, and also specifically supports teaching and learning activities. The attendance process is a process that supports teaching and learning activities, where attendance data is used in lectures as one of the references in making assessment decisions towards students. Attendance data is classified as data that is quite risky for damage, because its form is still in the form of sheets of paper. In order to minimize the attendance report damage, an Android-based application was designed that could manage the attendance process. The application that was built, in addition to handling attendance processes in lectures, also has an additional module which is an attendance recap where attendance data is stored, then recapitulated and displayed in a digital report that can be accessed anywhere and anytime. The design of the application also has a relatively small growth rate of data allocation, which is approximately 11.7MB, assuming lectures at the Indonesian Academy of Community in one semester.
\end{abstract}

Keywords: Attendance, Mobile Device, Android Mobile

\section{PENDAHULUAN}

Absensi adalah sebuah kegiatan pengambilan data guna mengetahui jumlah kehadiran pada suatu acara atau kegiatan. Setiap kegiatan yang membutuhkan informasi mengenai peserta tentu akan melakukan absensi. Hal ini juga terjadi pada proses belajar, kegunaan absensi ini terjadi pada pihak mahasiswa dan pihak pengada proses belajar mengajar. Salah satu kegunaan absensi ini kepada mahasiswa dalam perhitungan kemungkinan mahasiswa untuk mengikuti ujian dan salah satu kegunaan informasi absensi ini kepada pihak pengada kegiatan belajar mengajar antara lain untuk melakukan evaluasi kepada kepuasan mahasiswa terhadap suatu mata kuliah dan pembuatan tolak ukur ke depan guna pemberian ilmu yang lebih baik. [1]
Sistem absensi adalah hal yang penting dalam sebuah perkuliahan seabagai pencatat kehadiran mahasiswa. Di Kampus Akademi Komunitas Semen Indonesia (AKSI) Gresik, kehadiran menentukan seorang mahasiswa berhak atau tidak untuk mengikuti Ujian Akhir Semester dengan persentase 80\% dari 16 pertemuan dalam satu semester. Saat ini absensi perkuliahan di Akademi Komunitas Semen Indonesia (AKSI) dilakukan secara konvensional yaitu mahasiswa menandatangani form absensi kehadiran berdasarkan mata kuliah yang sedang dilakukan. Pengambilan data absensi secara manual memiliki banyak kekurangan, seperti data yang tidak valid ketika data yang masuk salah, hilang atau rusaknya data yang ada. Lembaran kertas yang menjadi alat absensi digunakan selama masa perkuliahan satu semester berlangsung, sehingga kertas yang digunakan umumnya mudah mengalami kerusakan. Permasalahan media kertas tersebut 
yangmelatarbelakangi kebutuhan terhadap aplikasi yangdapat menangani proses absensi, dan setidaknya mengurangi tingkat resiko kerusakan dari data absensi yang telah dihasilkan sangat diperlukan.

Perangkat mobile seperti layaknya smartphone mewabah dengan cepat di tangan masyarakat. Seiring dengan didukungnya pengembangan aplikasi mobile yang kian inovatif, menjadikan smartphone semakin digemari. Aplikasi yang dibangun guna mendukung konten dari smartphone tersebut tergolong sangat beragam, mulai dari hiburan atau permainan, alat hitung, pengolahan gambar, pemutar musik dan video, media sosial, dan sebagainya. Aplikasi pendukung konten smartphone memungkinkan untuk mempermudah hampir segala aspek kegiatan yang dijalani pengguna, baik itu hiburan, bisnis kerja, dan juga aspek lainnya. Perangkat mobile telah mampu melakukan pengolahan file digital yang umum digunakan dalam hampir segala aspek perkuliahan. Keunggulan lain yang dimiliki oleh perangkat mobile adalah tingkat mobilitas yang tinggi, sehingga pengolahan file tersebut dapat dilakukan dimana saja dan kapan saja. [2]

Terkait dengan permasalahan berkas absensi yang memiliki resiko kerusakan yang tinggi dan kemampuan perangkat mobile yang mampu mengolah berkas digital yang memungkinkan untuk menangani permasalahan sistem absensi yang ada, maka munculah dasar pemikiran pembuatan aplikasi yang dapat menangani permasalahan absensi mahasiswa yang terjadi dalam dunia perkuliahan. Kemampuan android sebagai perangkat yang canggih, dirasa sangat mampu untuk menangani permasalahan yang ada. Aplikasi yang dibangun diharapkan mampu menangani pengolahan data dalam sistem absensi sehingga menghasilkan informasi yang dibutuhkan seperti data rekapitulasi, serta mengatasi permasalahan kerusakan data absensi. [3]

Penelitian yang membahas mengenai sistem informasi absensi juga pernah dilakukan oleh [4] dan [5] dengan menggunakan platform Android dan pengujian dengan beberapa metode.

Batasan Objek dari penelitian ini adalah mahasiswa hanya bisa absen saat mengikuti mata kuliah yang sedang berlangsung di kampus Akademi Komunitas Semen Indonesia. Selain itu, tujuan dari penelitian ini mengembangkan sistem aplikasi absensi menggunakan platform Android. Manfaat penelitian ini menimimalisir terjadinya kesalahan dan kehilangan data absensi mahasiswa.

\section{METODE PENELITIAN}

Metode dari penelitian ini, menggunakan metode Waterfall. Pertama Requirement (Identifikasi) yang meliputi Observasi, Wawancara, dan Studi Pustaka. Kedua adalah Perancangan Sistem yng meliputi Data Flow Diagram (DFD), Use Case Mahasiswa, Entitas Dosen dan Activity Diagram. Data Flow Datagram (DFD) dan Use Case Mahasiswa dan Dosen seperti Gambar 1 dan Gambar 2 sebagai berikut:

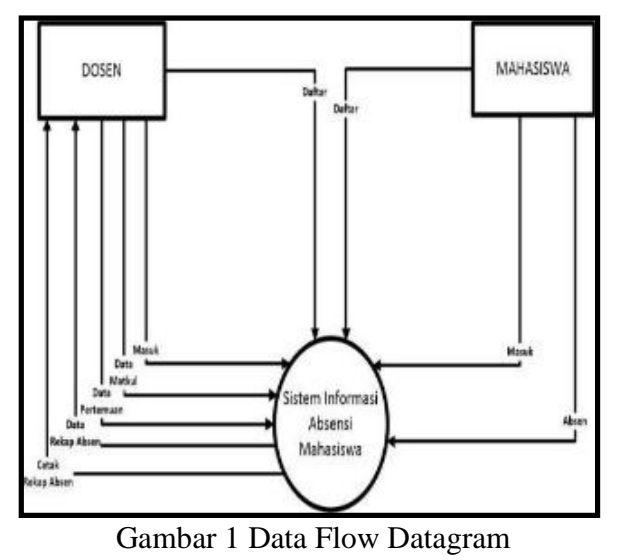

Pada Usecase Dosen, Dosen dapat melakukan:

1. Login: memasukkan username pribadi beserta passwordnya

2. Jadwal matakuliah: dosen menambahkan matakuliah apa saja yang diampu, ruang kelas, waktu, dan hari

3. Pertemuan:

- Barcode kelas digunakan saat mahasiswa sedang absen untuk meghadiri mata kuliah yang sedang berlangsung di tempat kelas yang ditentukan dosen

- Hanya dosen yang dapat melihat rekapan absen siapa saja yang telah hadir saat aktif kuliah.

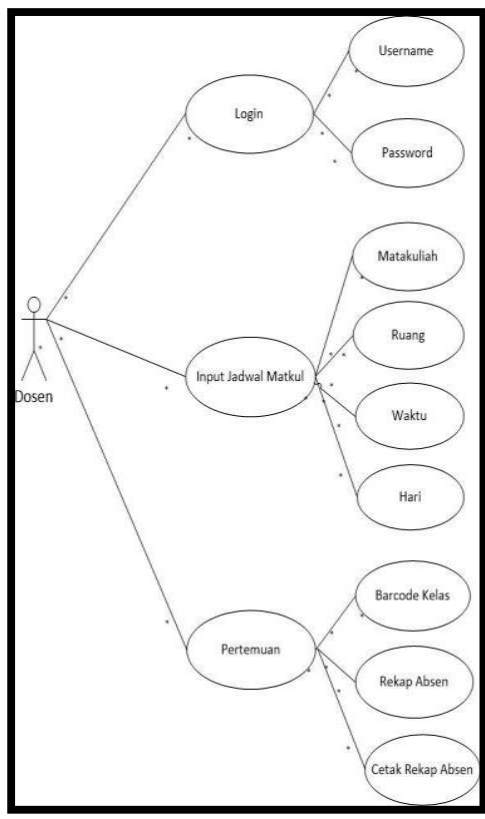

Gambar 2 Usecase Dosen

Pada Usecase Mahasiswa pada Gambar 3, Mahasiswa dapat melakukan login dengan memasukkan username individu dan passwordnya. Serta mahasiswa dapat melakukan absensi untuk mengikuti mata kuliah yang sedang berlangsung dengan menggunakan barcode kelas dari dosen. Sehingga tidak terjadi kecurangan absensi, absensi yang dilakukan mahasiswa melalui aplikasi android secara sistem barcode kelas. 


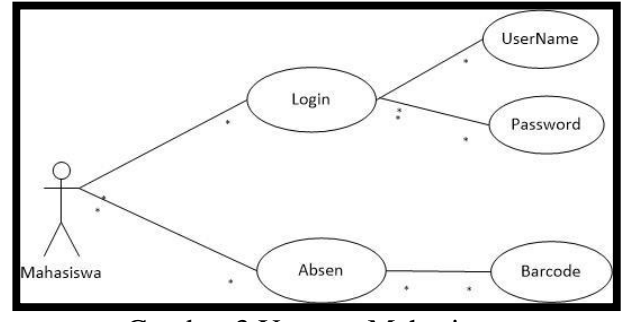

Gambar 3 Usecase Mahasiswa

Ketiga berkaitan dengan Entitas Relationship Diagram, yang terdiri dari sebagai berikut:

a. Entitas Dosen

Entitas dosen merupakan entitas yang berisikan tentang detail data yang dimiliki oleh masing-masing dosen yang berkaitan dengan aplikasi absensi ini.

b. Entitas Matakuliah

Entitas matakuliah merupakan entitas yang berisikan tentang detail data yang dimiliki oleh suatu matakuliah.

c. Entitas Mahasiswa

Entitas mahasiswa merupakan entitas yang berisikan tentang detail data yang dimiliki oleh mahasiswa dan berkaitan dengan penggunaan aplikasi absensi ini.

d. Entitas Perkuliahan

Entitas perkuliahan merupakan entitas yang terbentuk dari relasi antara entitas dosen dengan entitas matakuliah. Entitas perkuliahan, pada kenyataannya merupakan perlambangan dari jadwal pertemuan suatu matakuliah yang diampu oleh entitas dosen, dan diikuti oleh entitas mahasiswa.

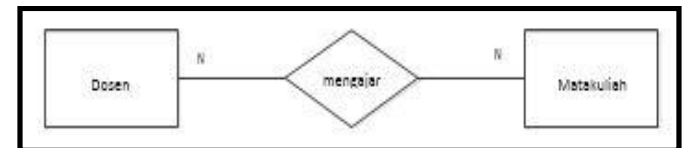

Gambar 4 Relasi Entitas Dosen dengan Entitas Matakuliah

Relasi yang terjadi pada entitas dosen dengan entitas matakuliah digambarkan pada Gambar 4, dimana 1 dosen mampu mengajar banyak matakuliah, dan juga ada beberapa matakuliah yang diajarkan oleh 1 dosen. Relasi banyak-ke-banyak merupakan relasi yang terbentuk antara kedua entitas tersebut. Relasi antara dosen dengan matakuliah, menghasilkan suatu entitas baru, yaitu entitas perkuliahan.

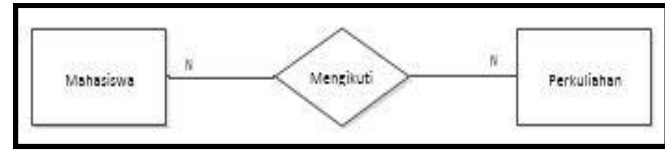

Gambar 5 Relasi Entitas Mahasiswa dengan Entitas Mata kuliah

Entitas hasil dari relasi antara entitas dosen dengan matakuliah, yaitu entitas perkuliahan, memiliki relasi tersendiri dengan entitas mahasiswa dalam pelaksanaan proses absensi dan kuliah yang berlangsung secara berkala. Relasi antara kedua entitas tersebut dapat dilihat pada Gambar 5 dimana relasi "Mengikuti" merupakan penggambaran relasi yang cocok.
Keempat adalah Activity Diagram yang terdiri dari Mahasiswa Daftar, Login, Dosen Daftar dan Dosen Login.

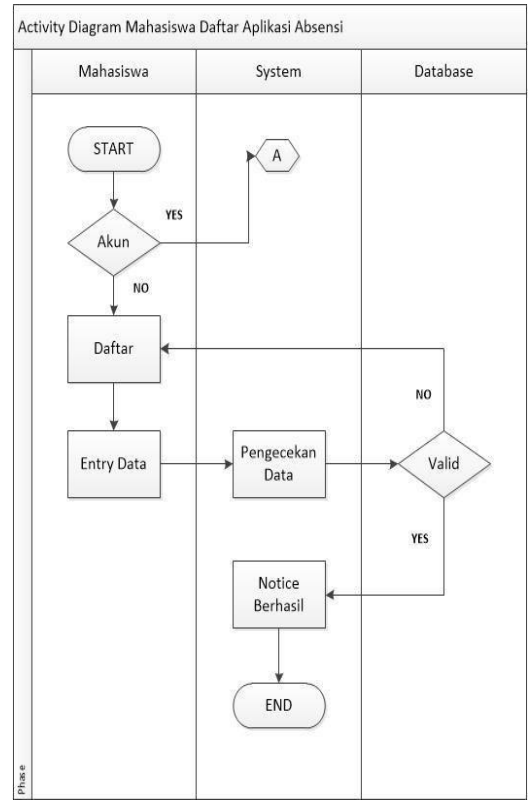

Gambar 6 Activity Diagram Mahasiswa Daftar

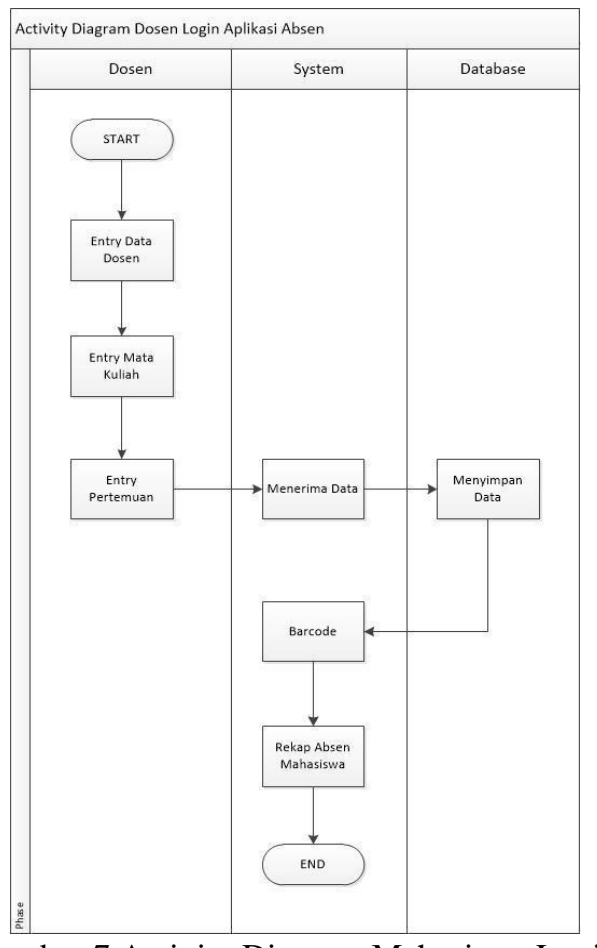

Gambar 7 Activity Diagram Mahasiswa Login 


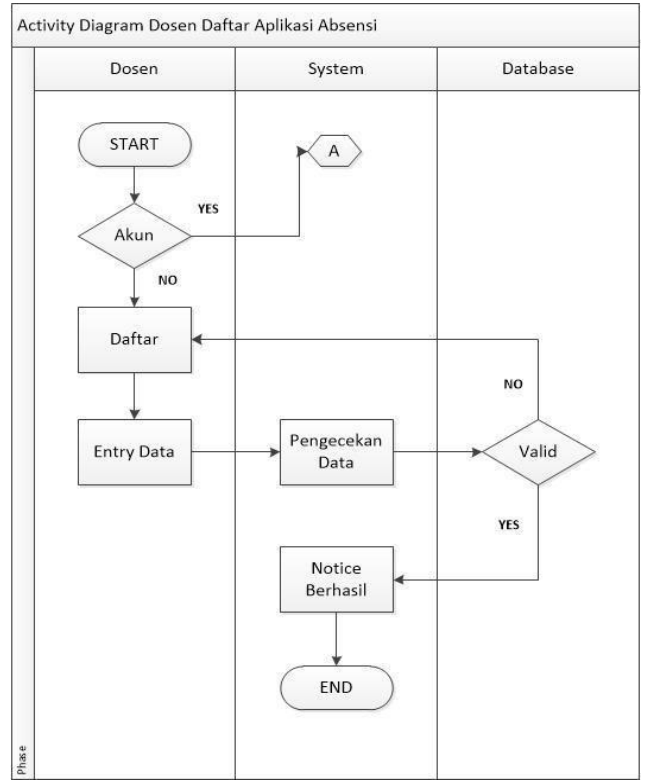

Gambar 8 Activity Diagram Dosen Daftar

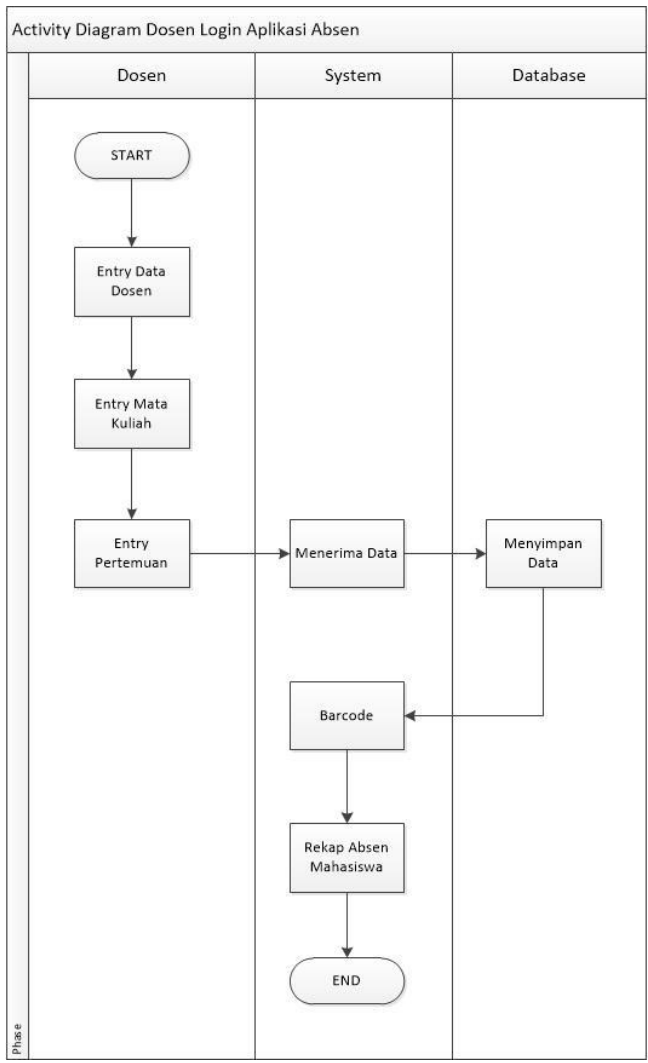

Gambar 9 Aktifitas Diagram Dosen Login

\section{HASIL DAN PEMBAHASAN}

Dalam penelitian ini rancangan pengujian sistem dilakukan dengan melakukan pengujian black-box terhadap semua fungsi dalam aplikasi. Pengujian blackbox merupakan salah satu pengujian aplikasi atau perangkat lunak yang berfokus pada persyaratan fungsional perangkat lunak. Karena itu uji coba black-box memungkinkan pengembang software untuk membuat himpunan kondisi input yang akan melatih seluruh syaratsyarat fungsional suatu program.
Pengujian Blackbox merupakan pengujian yang dilakukan untuk menguji sistem dengan data benar dan salah sebagai bahan pengujian.

Dalam sistem ini parameter pengujian yang digunakan data valid dalam aplikasi. Sehingga jika digunakan untuk menguji data salah maka otomatis hasil uji tidak berjalan.

a. Pengujian Daftar Dosen

Pengujian daftar dosen terbagi menjadi 2, yaitu dengan pengujian data benar dan pengujian data salah. Berikut adalah hasil pengujian daftar dosen data benar:

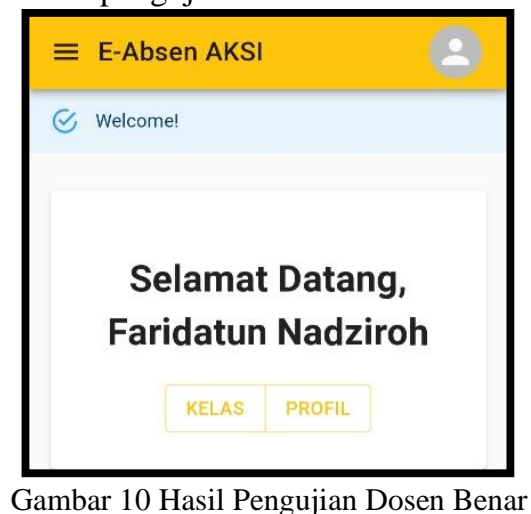

Berdasarkan hasil pengujian, dapat disimpulkan bahwa jika proses Daftar Dosen benar dengan memasukkan nama, nip, password, masukkan ulang password maka akan muncul tampilan seperti gambar diatas. Dan akan tampil pesan "welcome" Selanjutnya, dosen telah bisa mengakses Aplikasi Absensi Mahasiswa. Berikut adalah hasil pengujian daftar dosen data salah.

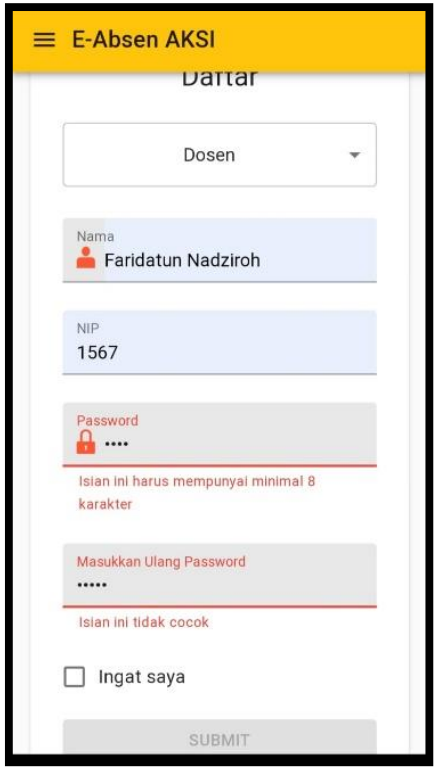

Gambar 11 Hasil Pengujian Daftar Dosen Salah

b. Pengujian Daftar Mahasiswa

Pengujian daftar mahasiswa terbagi menjadi 2, yaitu dengan pengujian data benar dan pengujian data salah. Berikut adalah hasil pengujian daftar mahasiswa data benar. 


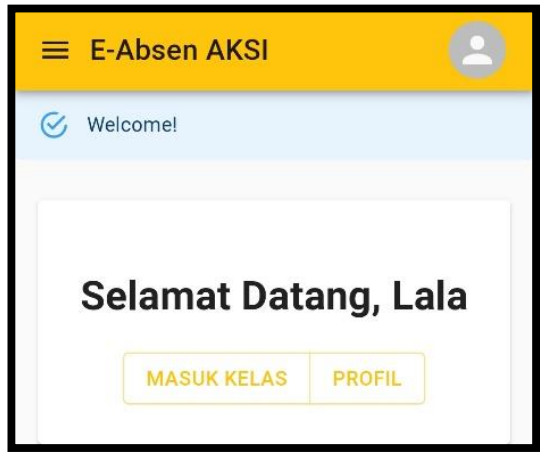

Gambar 12 Hasil Pengujian Daftar Mahasiswa Benar

Berdasarkan Gambar 12, dapat disimpulkan proses Daftar Mahasiswa benar dengan memasukkan nama, nim, password, masukkan ulang password maka akan muncul tampilan pesan "welcome" Selanjutnya, mahasiswa telah bisa mengakses Aplikasi Absensi Mahasiswa.

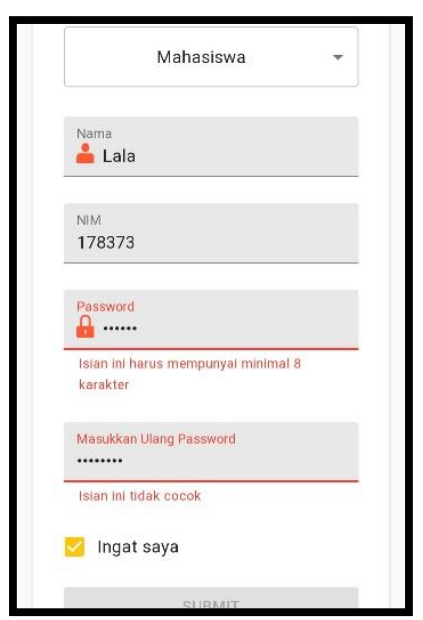

Gambar 13 Hasil Pengujian Daftar Mahasiswa Salah

Daftar Gambar 13, dapat disimpulkan jika terjadi kesalahan dalam memasukkan password dan masukkan ulang password, maka tampilan akan seperti gambar diatas yang menunjukkan tidak dapat disubmit. Jika dalam proses daftar terus menampilkan pesan tersebut, maka user tidak akan bisa mengakses Aplikasi Absensi Mahasiswa

\section{c. Pengujian Masuk Dosen}

Pengujian masuk dosen terbagi menjadi 2, yaitu dengan pengujian data benar dan pengujian data salah. Berikut adalah hasil pengujian masuk dosen data benar.

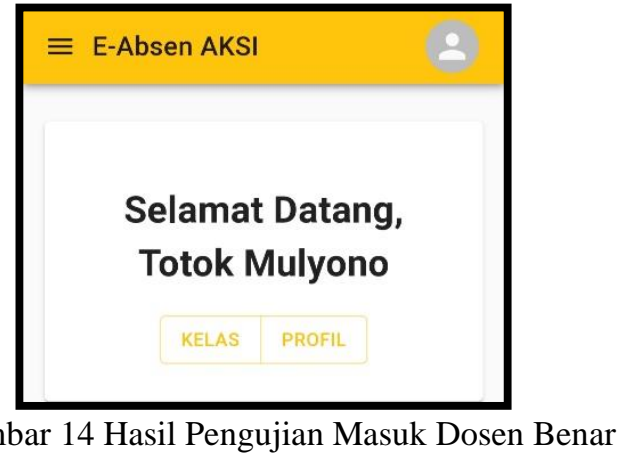

Berdasarkan Gambar 14, dapat disimpulkan bahwa jika proses masuk dosen benar dengan memasukkan nip, dan password, maka akan muncul tampilan seperti gambar diatas. Selanjutnya, dosen telah bisa mengakses Aplikasi Absensi Mahasiswa. Berikut adalah hasil pengujian masuk dosen data salah:

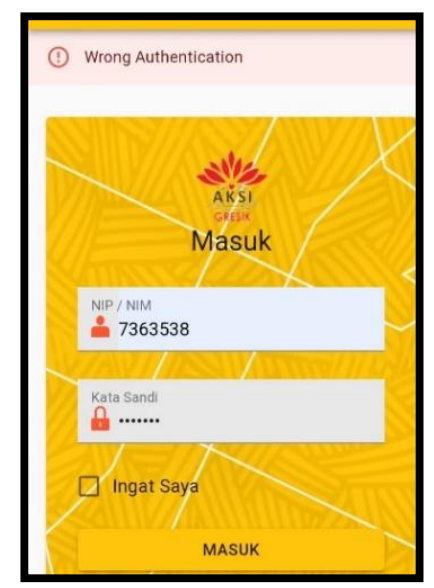

Gambar 14 Hasil Pengujian Masuk Dosen Salah

Berdasarkan Gambar 15, dapat disimpulkan bahwa jika terjadi kesalahan dalam memasukkan password, maka tampilan akan seperti gambar di atas yaitu muncul tampilan pesan "Wrong Authentication". Jika dalam proses masuk terus menampilkan pesan tersebut, maka user tidak akan bisa mengakses Aplikasi Absensi Mahasiswa.

d. Pengujian Masuk Mahasiswa

Pengujian masuk mahasiswa terbagi menjadi 2, yaitu dengan pengujian data benar dan pengujian data salah. Berikut adalah hasil pengujian masuk mahasiswa data benar. 


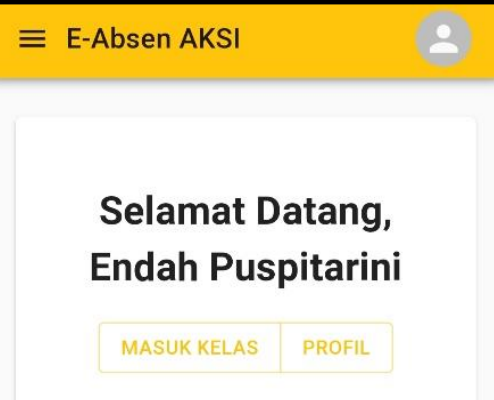

Gambar 15 Hasil Pengujian Masuk Mahasiswa Benar

Berdasarkan Gambar 16, dapat disimpulkan bahwa jika proses masuk mahasiswa benar dengan memasukkan nim, dan password, maka akan muncul tampilan seperti gambar diatas. Selanjutnya, mahasiswa telah bisa mengakses Aplikasi Absensi Mahasiswa.

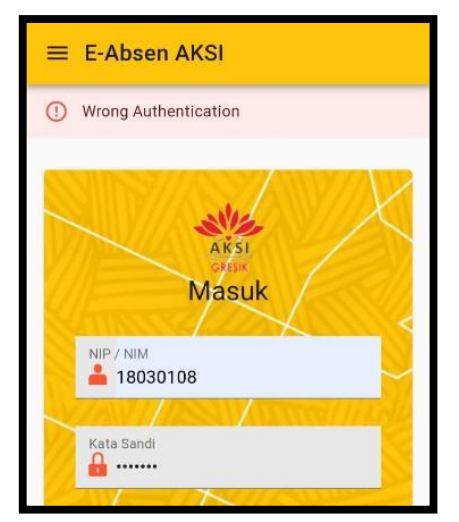

Gambar 17 Hasil Pengujian Masuk Mahasiswa Salah

Berdasarkan Gambar 17, dapat disimpulkan bahwa jika terjadi kesalahan dalam memasukkan password, dengan muncul "Wrong Authentication". Jika dalam proses masuk terus menampilkan pesan tersebut, maka user tidak akan bisa mengakses Aplikasi Absensi Mahasiswa

\section{e. Pengujian Membuat Mata Kuliah}

Pengujian membuat matakuliah, terbagi menjadi 2, yaitu dengan pengujian data benar dan pengujian data salah. Berikut adalah hasil pengujian membuat matakuliah data benar:

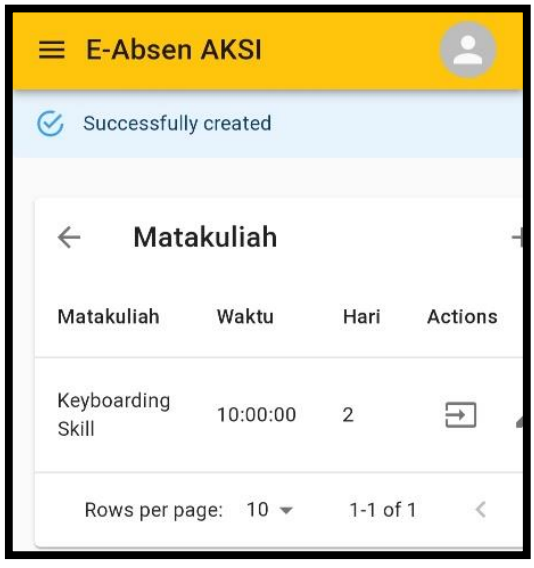

Gambar 18 Hasil Pengujian Membuat Matakuliah Benar

Berdasarkan Gambar 18, dapat disimpulkan bahwa jika proses membuat matakuliah benar dengan memasukkan matakuliah, ruang, waktu, hari. Selanjutnya, mahasiswa telah bisa mengakses Aplikasi Absensi Mahasiswa

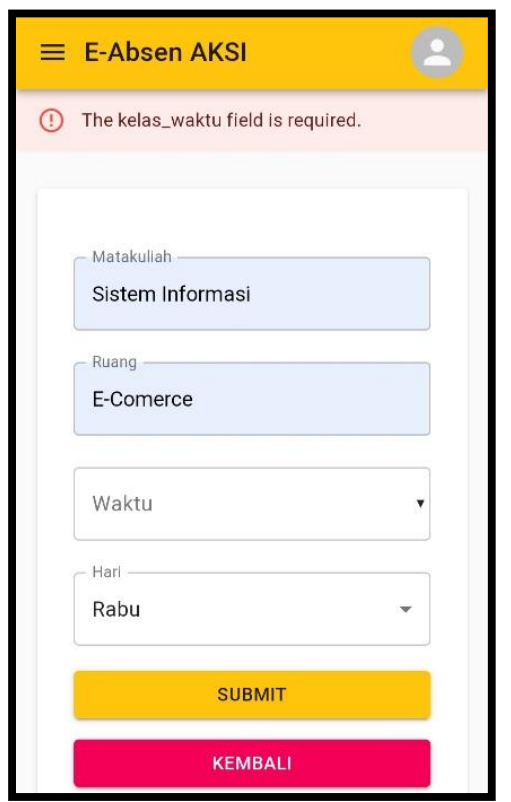

Gambar 19 Hasil Pengujian Membuat Mata Kuliah Salah

Berdasarkan Gambar 19, dapat disimpulkan bahwa jika terjadi kesalahan dalam memasukkan waktu, muncul tampilan pesan "The kelas_waktu field is required". Dan jika dalam proses membuat matakuliah terus menampilkan pesan tersebut, maka user tidak akan bisa mengakses Aplikasi Absensi Mahasiswa.

f. Pengujian Barcode Kelas

Pengujian barcode kelas terbagi menjadi 2, yaitu dengan pengujian data benar dan pengujian data salah. Berikut adalah hasil pengujian barcode kelas data benar: 


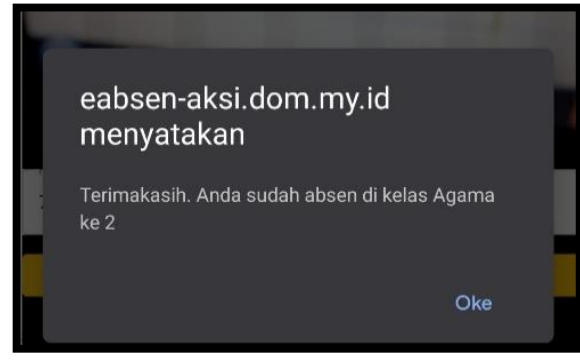

Gambar 20 Hasil Pengujian Barcode Kelas Benar

Berdasarkan Gambar 20, dapat disimpulkan bahwa jika proses barcode kelas benar dengan mengarahkan android ke layar pc untuk memindai barcode maka akan muncul tampilan seperti gambar diatas. Itu berarti mahasiswa sudah berhasil absen. Berikut adalah hasil pengujian barcode kelas data salah:

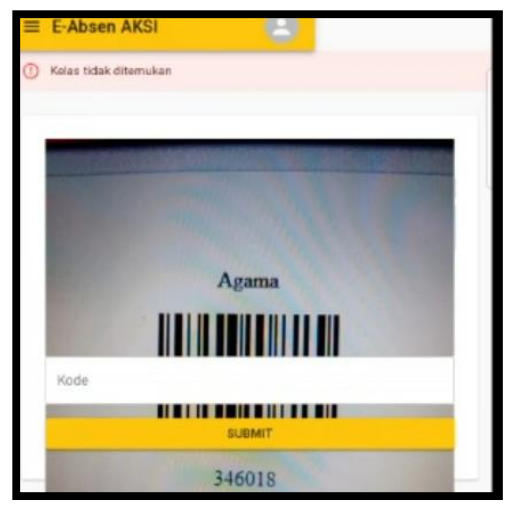

Gambar 21 Hasil Pengujian Barcode Kelas Salah

Berdasarkan Gambar 21, dapat disimpulkan bahwa terjadi kesalahan dalam memindai barcode, maka tampilan akan seperti gambar diatas yaitu muncul tampilan pesan "kelas tidak ditemukan". Jika dalam proses barcode kelas terus menampilkan pesan tersebut, maka mahasiswa tidak berhasil absen.

\section{Analisa Sistem dan Hasil Responden}

Secara umum program aplikasi absensi mahasiswa di Akademi Komunitas Semen Indonesia Gresik ini telah berhasil diimplementasikan dengan baik. Hal ini dibuktikan dengan hasil pengujian aplikasi absensi mahasiswa, dimana penulis meminta bantuan kepada 20 (dua puluh) responden mahasiswa Akademi Komunitas Semen Indonesia. Dari hasil pengujian penulis mendapatkan data sebagai berikut:

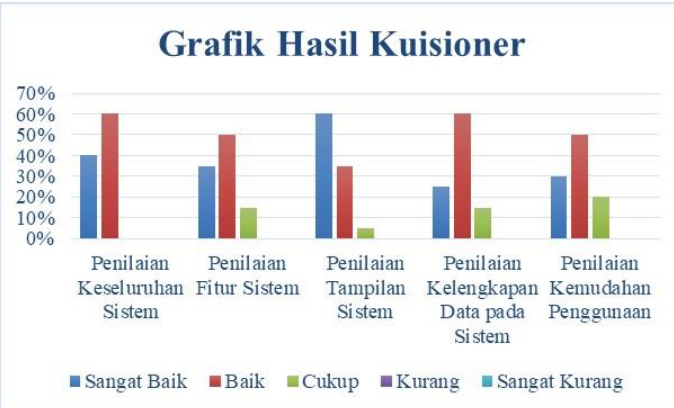

Gambar 22. Grafik Analisa Hasil Responden

Nilai Pengujian untuk kuesioner adalah Sangat Baik Skala 5, Baik skala 4, Cukup Skala 3, Kurang skala 2, Sangat Kurang skala 1. Hasil kuesioner ditunjukkan pada Tabel 1.

Tabel 1 Hasil Penilaian Responden

\begin{tabular}{lcccccccc}
\hline \multicolumn{1}{c}{ Pemyataan } & \multicolumn{1}{c}{ Penilaian } & \multicolumn{1}{c}{ Skor } & Rata-Rata \\
& SB & B & C & K & SK & & \\
\hline Penilaian Keseluruhan Sistem & 40 & 48 & 0 & 0 & 0 & 88 & 8,8 \\
\hline Penilaian Fitur Sistem & 35 & 40 & 9 & 0 & 0 & 84 & 8,4 \\
Penilaian Tampilan Sistem & 60 & 35 & 3 & 0 & 0 & 98 & 9,8 \\
Penilaian Kelengkapan Data pada Sistem & 25 & 48 & 9 & 0 & 0 & 82 & 8,2 \\
\hline Penilaian Kemudahan Penggunaan Sistem & 30 & 40 & 12 & 0 & 0 & 82 & 8,2 \\
\hline
\end{tabular}

Berdasarkan hasil penilaian responden seperti Tabel 1 di atas, maka disimpulkan hasil rata-rata penilaian untuk Sistem Aplikasi Absensi Mahasiswa adalah sebesar 86,8 dengan skala 10. Menurut interpretasi skala likert mulai dari $61 \%-80 \%$, aplikasi absensi mahasiswa dinyatakan layak. Maka sistem telah disetujui penggunaannya dan memiliki nilai efektif untuk menunjang kemudahan mahasiswa dan dosen yang berkaitan dengan sistem tersebut.

\section{Kesimpulan}

Dari hasil observasi, perancangan, uji coba, dan analisa yang telah dilakukan tentang dibuatnya Aplikasi Absensi Mahasiswa Berbasis Android, penulis dapat menyimpulkan beberapa tujuan sebagai berikut :

1. Aplikasi absensi mampu menangani sebagaian besar proses absensi yang berlangsung dalam lingkup perkuliahan mahasiswa

2. Aplikasi berjalan pada perangkat mobile dengan platform android yang mana telah umum digunakan sehingga mempermudah user dalam penggunaan aplikasi.

3. Aplikasi telah mampu mengolah data absensi menjadi informasi rekapitulasi data absensi yang digunakan sebagai suatu acuan bagi pihak dosen untuk melakukan penilaian terhadap mahasiswa

\section{Saran}

Saran yang dapat dikembangkan dari penelitian ini adalah:

1. Agar pemanfaatan aplikasi absensi mahasiswa lebih baik, sebaiknya untuk penelitian selanjutnya perlu pengembangan yang lebih lanjut mengenai fitur - fitur yang telah ada. 
2. Sehubungan dengan perbaikan sistem, maka aplikasi absensi mahasiswa pada platform android yang telah dirancang khusus untuk mempermudah pekerjaan dapat dipelihara dengan baik dan dikembangkan sesuai kebutuhan ada.

3. Agar menjaga keamanan data yang tersimpan di dalam database, perlu diadakan sinkronisasi database secara berkala.

4. Agar aplikasi absensi pada platform android diimplementasikan oleh Akademi Komunitas Semen Indonesia.

\section{Daftar Pustaka}

[1]Albert Suwandhi, (2017), “Aplikasi Absensi Kehadiran Mahasiswa STMIK IBBI Menggunakan QR Code Berbasis Web dan Android” Jurnal Ilmiah Core IT, Vol.7 No.2, hal 149-155

[2]Ermatita, Rahmat, dan Miftahul, (2017), "Pengembangan Sistem Absensi Menggunakan QR Code Reader Berbasis Android (Studi Kasus: Fakultas Ilmu Komputer Jurusan Sistem Informasi Unsri”, Konferensi Nasional Teknologi Informasi dan Aplikasinya. Vol 4, hal 45-50.

[3] Taronisokhi, dan Pristiwanto, (2017), "Pembangunan Web Mobile Absensi Mahasiswa Pada Platform Android Yang Terintegrasi Dengan Website Utama Sistem Informasi Akademik (SIA) STMIK Budi Darma" Jurnal Teknik Informatika Unika St. Thomas, Vol.2, No.2, hal 100-102

[4] Wahyu, Yulianingsih, dan Sri, (2018), "Pengujian Black Box Testing Pada Aplikasi Action \& Strategy Berbasis Android Dengan Teknologi Phonegap" Satuan Tulisan Riset dan Inovasi Teknologi (String), Vol.3, No.2, hal 206-210

[5] Syaifullah, I Gede, dan Ario, (2018), "Sistem Informasi Kepuasan Layanan Administrasi Akademik Berbasis IPA(Importance Performance Analysis) Studi kasus Fakultas Teknik Universitas Mataran "Vol.2 No.1, hal 37-43. 